УДК 342.5

\title{
ПОНЯТИЕ УПРАВЛЕНЧЕСКОГО РЕШЕНИЯ В ДЕЯТЕЛЬНОСТИ ТАМОЖЕННЫХ ОРГАНОВ: ПРАВОВОЙ И ОРГАНИЗАЦИОННЫЙ АСПЕКТ
}

\author{
В.Б. ШАБАНОВ \\ д-р юрид наук, профессор, начальник кафедры специальных дисциплин, г. Минск \\ B.H. АНАНЬЕВА \\ Заместитель начальника \\ Государственный институт повышения квалификации и переподготовки кадров \\ таможенных органов Республики Беларусь, г. Минск
}

Аннотация

В работе рассматриваются проблемы принятия управленческих решений как основы эффективного функиионирования организации, в частности, таможенных органов. Изложены алгоритм принятия управленческих решений в контексте профессиональной деятельности таможенных органов, в том числе, с точки зрения реализации правоотномений.

Abstract
The article deals with the problem of managerial decision-making as the basis for the effective functioning of the organization, in particular, the customs authorities. Algorithms for management decision-making in the context of professional activity of customs authorities, including, in terms of the implementation of relations.

\section{ВВЕДЕНИЕ}

Управление - это процесс воздействия на систему для перевода ее из одного состояния в другое или поддержания ее в установленном режиме.

Социальное управление - это объективно необходимая разновидность социальной деятельности, состоящая в сознательном и целенаправленном организационном воздействии субъекта управления на различные социальные системы для повышения эффективности их функционирования, приведение в соответствии с закономерностями развития. Данное воздействие может осуществляться только путем принятия и реализации управленческих решений.

Принятие решений в деятельности таможенных органов - это важный и сложный процесс. Тем не менее многие руководители полагают, что принятие решений - это выбор одного из нескольких возможных вариантов действий. Следует отметить, что решения подобного рода представляют собой всего лишь один шаг сложного и динамичного процесса.

\section{РЕЗУЛЬТАТЫ И ИХ ОБСУЖДЕНИЕ}

Можно выделить два типа элементов качественного процесса принятия решений руководством таможенных органов: ряд последовательных шагов (инициирование процесса, диагностика, формирование и выбор альтернатив, реализация и оценка); учет важнейших факторов (право принимать решения, межличностные отношения, выбор времени и обмен информацией). Каждый компонент может быть связан с одним или всеми компонентами.

Самое страшное в управлении - это не плохое решение, а отсутствие решения. Для того чтобы научиться принимать правильные решения, руководству разного уровня необходимо принимать много решений. Управленческий опыт можно было бы определить как сумму принятых решений. Несмотря на такое количественное выражение, опыт как бы приобретает качественную окраску. Это выражается в том, что обобщенный опыт становится ключевой составляющей интуиции, т.е. предчувствия, воображения, проницательности, мысли, которые спонтанно проявляются в сознательном постижении проблемы и последующем ее решении. В реальной деловой активности факты и цифры нередко проявляются без видимой связи со стоящей за ними проблемой.

Ч.Грегг в своей работе «Мудрость нельзя передать словами» пишет: «Бизнес, по крайней мере, сегодня, не является точной наукой. Не существует в природе единственно верного ответа на деловую проблему. Для студента или для менеджера невозможно взять книгу и найти в ней путь к правильному решению. В каждой деловой ситуации всегда есть обоснованная возможность того, что правильный ответ на нее еще не найден - даже преподавателями»[1].

В настоящее время существуют различные мнения о понятии «решение». В Большой советской энциклопедии ему дается следующее определение: «Решение - один из необходимых моментов волевого действия, состоящий в выборе цели действия и способов его выполнения. Волевое действие предполагает предварительное осознание цели и средств действия... мысленное обсуждение оснований, говорящих за или против его выполнения и т.п. Этот процесс заканчивается принятием решения» [2].

Решение можно определить как обязательное к исполнению общественно необходимых действий установление, сознательный акт субъекта управления, связанный с выбором цели и путей ее достижения [3]. 
В жизни каждый принимает десятки и сотни решений. К решениям относятся как малозначащий выбор одежды и просмотр телевизионных программ, так и выбор места работы или вуза для получения образования.

В силу неосознаваемых психологических факторов часто непропорционально много внимания уделяется одним решениями пренебрегается значимость других. Многие решения принимаются без должного систематического обдумывания. Однако в управлении принятие решения - это более систематизированный процесс, чем в частной жизни.

Управленческие решения в системе таможенных органов - выбор альтернативы, осуществленный руководителем в рамках его должностных полномочий, компетенции и направленный на достижение целей по обеспечению экономической безопасности.

Что отличает управленческое решение от частного выбора?

Во-первых, цели. Субъект управления (будь то один или группа) принимает решение исходя не из своих собственных потребностей (хотя их влияние и играет определенную роль), а в целях решения проблем конкретной организации, в частности таможни.

Во-вторых, последствия. Частный выбор индивида сказывается на его собственной жизни и может повлиять на немногих близких ему людей (например, руководитель, особенно высокого ранга, выбирает направление действий не только для себя, но и для организации в целом и ее работников, его решения могут существенно повлиять на жизнь многих людей).

В-третьих, разделение труда. Если в частной жизни человек, принимая решение, как правило, сам его и выполняет, то в организации существует определенно разделение труда: одни работники заняты решением возникающих проблем и принятием решений, а другие - их выполнением.

В-четвертых, профессионализм. В частной жизни каждый человек самостоятельно принимает решения в силу его интеллекта и опыта. В управлении организацией принятие решений - гораздо более сложный, ответственный и формализованный процесс, требующий профессиональной подготовки.

Выделяют два уровня решений в организации: индивидуальный и организационный (см. таблицу 1).

Принятие решения в организации - сознательная и целенаправленная деятельность, осуществляемая человеком; поведение, основанное на фактах и ценностных ориентирах; процесс взаимодействия членов организации; выбор альтернатив в рамках социального и политического состояния организационной среды; часть общего процесса управления; неизбежная часть ежедневной работы; важный момент для выполнения всех других функций управления.

Принятие правильного решения - это область управленческого искусства. Способность и умение делать это развиваются с опытом, приобретаемым руководителем на протяжении всей жизни. Совокупность первого и второго знания и умения составляют компетентность любого руководителя. В зависимости от достигнутого уровня компетентности, говорят об эффективности работы руководителей разного уровня таможенных органов.

Таблица 1 - Уровни принятия решений в организации

\begin{tabular}{|l|l|}
\hline \multicolumn{2}{|c|}{ Проблемы } \\
\hline Решение на уровне индивида & Решение на уровне организации \\
\hline Наличие индивидуального умения & Создание соответствующей среды \\
\hline Важен процесс принятия решения как такового & Важно принятие решения к определенному моменту \\
\hline Классификация решений & Вовлечение всех уровней управления \\
\hline Имеет дело с ошибками в решениях & Имеет дело с неопределенностью \\
\hline $\begin{array}{l}\text { Решение определяется } \\
\text { используемым индивидуальным стилем }\end{array}$ & $\begin{array}{l}\text { Решение носит групповой характер. Управление } \\
\text { групповым процессом }\end{array}$ \\
\hline Создание и выбор альтернатив & Управление творчеством и новаторством \\
\hline Взятие риска на себя & Выполнение решений \\
\hline
\end{tabular}

Принятие решений предполагает выбор первоочередных задач и дел. Принять решение - значит установить приоритетность. Некоторые из основных проблем руководителей состоят в том, что они часто пытаются сразу выполнить большой объем работы; распыляют свои силы на отдельные, часто несущественные, но кажущиеся необходимыми дела.

Установить приоритетность - означает принять решение о том, каким из задач следует придавать первостепенное, второстепенное и т.д. значение.

Определение приоритетности - это настолько само собой разумеющееся дело, что часто выполняется не систематически и даже неосознанно. Следовательно, надо сознательно устанавливать однозначные приоритеты; последовательно и системно выполнять задачи, включенные в план, в соответствии с их очередностью.

Благодаря регулярному определению приоритетности предстоящих задач можно: работать только над действительно важными и необходимыми задачами; решать вопросы в соответствии сих неотложностью; концентрироваться на выполнении только одной задачи; более целеустремленно приступать к делу и укладываться в установленные сроки; наилучшим способом достигать поставленных целей при заданных обстоятельствах; исключить дела, которые могут быть выполнены другими; в конце планового периода выполнить важные вопросы; не оставлять невыполненными задачи, которые по силам.

Позитивными последствиями будут: соблюдение установленных сроков; получение удовлетворенности от рабочего дня и результатов работы; отсутствие конфликтов и стрессовых перегрузок. 
На пути к достижению целей управления постоянно возникают проблемы, ситуации, которые требуют своего разрешения. Каждая система управления решает их посредством принятия управленческих решений. Любое практическое действие начинается с того или иного решения. Следовательно, управленческое решение может рассматриваться не только как главная стадия (элемент, составная часть) процесса управления, но и основное средство достижения целей управления. В любой системе управления разрабатывается и принимается огромное количество решений.

Управленческое решение представляет собой программу действий, выраженную в форме предписания (директивы), содержащей постановку целей, определяющую трудовые и материальные ресурсы, пути и средства достижения этих целей, а также формы организующей деятельности субъектов и объектов управления в реализации решения [4].

Часто решение рассматривается как кульминационная точка управленческой деятельности, как действие, как документ, как программа разрешения противоречий в системе управления являющиеся результатом выбора между возможными вариантами на основе соединения знания и воли. В управленческой деятельности в целом, а в таможенных органах в частности, чаще всего это постоянный процесс преодоления противоречий, возникающих в ходе организации деятельности. Более того, это процесс творческий, требующий от руководителей глубоких профессиональных знаний, нестандартного мышления и широкого видения проблем, правильного использования разносторонней информации и опыта организатора, умения сочетать при выборе решений коллегиальность и единоначалие.

Управленческое решение всегда связано с определением цели достижения определенного результата. Для руководителей и иных работников, в той или иной мере участвующих в разработке управленческих решений, важным научно-практическим положением является системное видение решений. Оно позволяет оценивать приоритеты целей в условиях конкретной оперативной обстановки, уже на начальных стадиях разработки решения отыскивать не только проблемы, но и средства их разрешения, т.е. действовать целеустремленно, обеспечивать цикличность, преемственность решений, ритмичность и планомерность процесса их разработки и принятия, позволяет рассматривать каждое из них как звено в общей цепи постановки и реализации целей деятельности таможенных органов. Важно, чтобы руководитель, принимающий решение, видел его назначение, место и роль в системе решений, оценивал в соответствии с другими степень его влияния на выполнение стоящих перед, в частности, таможней, задач.

Основаниями принятия новых решений являются: указание вышестоящих субъектов; истечение срока действия предыдущего решения; необходимость корректировки прежнего решения; сбои, происходящие в системе управления; новое состояние объекта управления; изменение жизненной ситуации (т.е. внешней среды); изменение нормативной правовой базы [4].

\section{ВЫВОДЫ}

Несмотря на многообразие, решения обладают следующими общими признаками:

Во-первых, управленческое решение принимается людьми, следовательно, оно носит субъективный характер. Однако качество решения предопределяется прежде всего тем, в какой мере оно учитывает объективно существующие закономерности и связи в обществе. Знание закономерностей общественного развития, среды функционирования и состояния управляющей и управляемой систем, учет особенностей конкретной ситуации позволяют подходить с научных позиций к выработке решений.

Во-вторых, решение обладает директивным, властным характером и обязательно для тех, кому оно адресовано. Исполнение решения гарантируется, а при необходимости обеспечивается мерами принуждения. Это ни в коей мере не исключает обязанности субъекта управления, принявшего решение, вести разъяснительную и организационную работу в целях добровольного исполнения решения.

В-третьих, управленческие решения принимаются в результате либо согласования воли субъекта управления с волей другого участника управленческого отношения, либо одного лишь волеизъявления субъекта управления. Однако в том и другом случае решение принимается в одностороннем порядке. Оно исходит из компетентного органа, должностного лица - субъекта управления. Причем в таком же порядке принимаются и те решения, которые являются результатом совместных действий (на основе сотрудничества) нескольких, не связанных отношениями подчиненности органов - субъектов управления. В данном случае речь идет лишь о совместном решении, выражении коллективной воли в одностороннем порядке.

В-четвертых, управленческое решение либо устанавливает обязательные правила поведения, либо регулирует отдельные управленческие отношения. В последнем случае оно влечет возникновение, изменение или прекращение управленческих отношений (например, решение об освобождении лица от должности). Следовательно, решение может регулировать как абстрактные, так и конкретные общественные отношения в социальном управлении, и в этом смысле управленческое решение является решением-регулятором.

В-пятых, субъект управления обязан избрать оптимальный вариант решения. Процесс принятия и само решение носят творческий характер. Субъект управления решает вопросы, связанные с хозяйственной деятельностью, социально-культурным строительством, обеспечением экономической безопасности и т.п. Эта деятельность затрагивает прямо или косвенно интересы большого круга лиц, поэтому от субъекта управления требуются творческий и научный подход, предвидение, осмотрительность, учет и глубокий анализ физических данных.

В-шестых, управленческие решения принимаются субъектами управления (органы государства, общественные объединения и их органы, должностные лица) в пределах своей компетенции. Так, в таможенных органах субъектами подготовки и принятия решений являются руководители (начальники и их заместителя) отделов, служб и подразделений, уполномоченные на то работники (инспекторы) отраслевых служб и подразделений. Субъектами принятия теку- 
щих оперативных решений практически являются все сотрудники таможенных органов. В процессе своей деятельности им постоянно приходится иметь дело с возникающими в таможенной сфере задачами, проблемами, в том числе и конфликтными ситуациями, которые необходимо решать, чтобы достичь поставленных перед ними целей по борьбе с преступностью и иными правонарушениями. Компетенция центрального таможенного органа и его работников по принятию решений определяется соответствующими нормативными правовыми актами.

В-седьмых, управленческое решение принимается в установленном порядке.

\section{ЛИТЕРАТУРА}

1.Гвишиани Д.М. Организация и управление. Изд. 3-е, перераб М.; Изд-во МГТУ им. Н.Э.Баумана, 1988

2.БСЭ, изд. 2-е. Т. 36, М., 1955. С. 544.

3.Хорькин Ю.П., Силков М.В. Управленческие решения, их выработка и принятие: лекция Домодедово, 2002,C.6.

4.Основы управления в органах внутренних дел. М., 2003. С. 156.

Статья поступила в редакциию 13 июня 2015 года. 